IRA-International Journal of Applied Sciences ISSN 2455-4499; Vol.09, Issue 01 (October 2017)

Pg. no. $1-8$

Institute of Research Advances

https://research-advances.org/index.php/IRAJAS

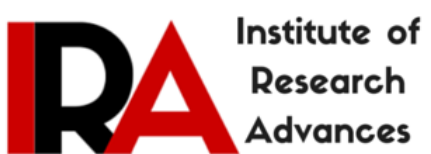

\title{
Determination of Some Mechanical and Thermal Properties of Cattle Manure Pellets
}

\author{
Javad Rezaeifar ${ }^{1}$, Mansoureh Pourjafar ${ }^{2}$ \\ ${ }^{1}$ Payamnoor University of Tehran, Iran. \\ ${ }^{2}$ Higher Educational Complex of Saravan, Saravan, Sistan and Baluchestan, Iran.
}

Type of Review: Peer Reviewed.

DOI: http://dx.doi.org/10.21013/jas.v9.n1.p1

\begin{abstract}
How to cite this paper:
Rezaeifar, J., Pourjafar, M.. (2017). Determination of Some Mechanical and Thermal Properties of Cattle Manure Pellets. IRA International Journal of Applied Sciences (ISSN 2455-4499), 9(1), 1-8. doi:http://dx.doi.org/10.21013/jas.v9.n1.p1
\end{abstract}

(C) Institute of Research Advances.

(cc) Br-No

This work is licensed under a Creative Commons Attribution-Non Commercial 4.0 International License subject to proper citation to the publication source of the work.

Disclaimer: The scholarly papers as reviewed and published by the Institute of Research Advances (IRA) are the views and opinions of their respective authors and are not the views or opinions of the IRA. The IRA disclaims of any harm or loss caused due to the published content to any party.

Institute of Research Advances is an institutional publisher member of Publishers Inter Linking Association Inc. (PILA-CrossRef), USA. The institute is an institutional signatory to the Budapest Open Access Initiative, Hungary advocating the open access of scientific and scholarly knowledge. The Institute is a registered content provider under Open Access Initiative Protocol for Metadata Harvesting (OAI-PMH).

The journal is indexed \& included in CAS Source Index of Chemical Abstracts Service of American Chemical Society (USA), WorldCat Discovery Service (USA), CrossRef Metadata Search (USA), WorldCat (USA), OCLC (USA), Open J-Gate (India), EZB (Germany) Scilit (Switzerland), Airiti (China), Bielefeld Academic Search Engine (BASE) of Bielefeld University, Germany, PKP Index of Simon Fraser University, Canada. 


\begin{abstract}
One of the important subsidiary materials of livestock units is excreta. The livestock waste (including the combination of the Cattle Manure and products case in the bed) as a valuable source of the minerals (Nitrogen $1.78 \%$, phosphor us 0.5\% and potassium 0.99\%).For the transportation of the cattle manure in the natural state is difficult and costly due to being low the special mass and the nature of mass. It is produced around 6 million thons the cattle manure yearly in Iran which it is usually filled in the place according to the lack of organic materials of the soils country, the use of the cattle manure causes increasing the productivity of crops. We usually need to some of the mechanical and thermal properties of the cattle manure for producing the pellet by Extruder, so we Survey some of the mechanical and thermal properties of the cattle manure pellet in this research such as the shear stress and the coefficient of thermal diffusivity cattle manure. We obtain the coefficient of the thermal diffusivity manure $(\boldsymbol{\alpha})$ from $2.11 \times 10^{-7}$ to $9.04 \times 10^{-8}$ in 3 repetitions with testing for four humidity surfaces $20,40,60,82 \%$ and in temperatures of 40,50, 60, 70 centigrade. Degrees And also the most shear stress is Obtained between the humidity contents of 40 and 50 and with increasing the percentage of humidity of the cattle manure, the sheer stress becomes reduced and this is due to that an intermolecular loan ding forces become loosed with increasing the humidity as a result we need lower force for cutting manure.
\end{abstract}

Keywords: Cattle manure, pellet, mechanical properties, thermal properties.

\title{
Introduction
}

With increasing the production of the dairy products and meaty, different kinds of by product and wastes is caused which these materials including the remains of plant production, an animal ancillary material, Biomass and soon. One the most important of an agricultural by- products is animal waste which due to the production of the dory products and meat, construction of the industrial big live stocks in border towns is developed and these livestock with producing and gathering a lot of manure in around of livestock imperil. The human health and environmental heath the daily production of animal waste with large volume and being high the amount of the humidity and also being low the density gradually is caused to change to the problem the paying and using 7 the manure of live stocks. Although one of the requirements is much production of livestock and poultry products and changing the live stocks or traditional farms to industrial farms but much production of the manure or an animal waste in big units of training the trap and birds is indispensable element of these units. Due to noting the fast way for recycling the manure, the catties must depot- off that. The fresh any produced in the cattle's have the humidity above $80 \%$ and so the depot manure is an appropriate place for grow thing the pathogens for traps. Furthermore, the depot manure is caused the publication of an ammonia, nitrogen oxides, goo, production files and Methane which they are destructive for ozone layer [2] Publication of these materials in the nature will cause creating an environmental pollution [3].A tight management in the catties and fast recycling the manure caused decreasing these problems one of these problems in the high humidity of fresh manure one of these ways that we can use for fast recycling of the cattle manure is drying by mixing and activating aerobic and anaerobic bacterizes the Dried manure have less pollution in to the fresh manure and this is as a source full of minerals (Nitrogen $1.78 \%$, phosphors $0.5 \%$, potassium $0.99 \%$ ) which they are very effective and helpful for feeding agricultural soils and recovering the physical and chemical properties of soils. One the best ways for solving these problems is use of forming technology and compression of livestock manure. We can form the manure in to a little cylinder with certain diameter and length which called pellet these cylinders in the fond processing industry. We can form the manure in to a little cylinder with certain diameter and length which called pellet these cylinders in the fond processing industry.

The compression process (pelt) is a reaction between the particles of material and after particles and the applied forces which is for increasing the density of the mass substance to decrease the value of them and form a certain form for facilitating the movement or in other industrial agricultural and animal husbandry process which this work is done by a machine which is called an Extruder Knowing some of the mechanical and thermal Properties and effective factors in compression equipment or forming is essential for calculating the press in the pellet production by Extender and determining the power. 


\section{Materials and methods}

The physical properties of the cattle manure change into the type of the cow (Heifers, bull, Cow) [5]. And also the properties of fresh manures change with rotten manure. Therefore, we prepare dried fertilized form the place of depot cattle manure which is accumulated more than one year mites in PardisAboreihan form (located in Ghezlagh village from Pakdasht city) and pass the processing steps and then use from this sample in whole experiments.

\section{Measuring the coefficient the thermal diffusivity from the cattle manure $(\alpha)$}

We usually use from Heating in production of pellet by Extruder. The thermal belt is closed on the cylindrical extruder [7] the heat is effective in stability of pellets especially in some of the materials and therefore the way of transforming the heat especially in a passing phase until getting to the final temperature which is important for the manure unstable conditions or transitional conditions is generally for heat conduction in the process heating or cooling of agricultural products. This function requires collection or decreasing hat in the bulk which finally caused changes in temperature in the bulk with passing time. Heat influence to the bulk with certain rat or porous layers of agricultural products and publish which depends to the coefficient of the thermal diffusivity of that material ( $\boldsymbol{\alpha})$ [6]. Now, we place the samples of the manures in an aluminum cylinder with thin call with length of $150 \mathrm{~mm}$ and diameter $7.5 \mathrm{~mm}$ for determining the coefficient of the thermal diffusivity $(\boldsymbol{\alpha})$. We place the thermocouple $\mathrm{T}$ on the central axis of the cylinder and in center of the height of that for reading the temperature the center of the sample.We place the cylinder with a sample in to the water with a certain temperature (for testing in temperatures $40,50,60,70 \mathrm{C}$, the temperature of water is respectively 50,60,70,80 C) until the sample and cylinder became isothermal with water then the cylinder with sample is placed in water bath with law temperature (for testing in temperatures $40,50,60,70 \mathrm{C}$ the temperature of the source is respectively $30,40,50,60 \mathrm{C}$ ) and the changes of the central temperature of the sample is recorded with use of data reader in computer (CHY 502 A, Taiwan).

(figure 1) we can adjust the temperature of water bath between 10 until $80 \mathrm{C}$ by an agitator and cooler (for testing in low temperatures ) or heaters which is connected to thermostat (for testing in high temperatures), if it is necessary to adjust temperature between 10 to $300 \mathrm{C}$, We can use from liquid ail. The temperature of bath should adjust to form and thermal gradient from outside to inside of the cylinder and conversely in two minutes.

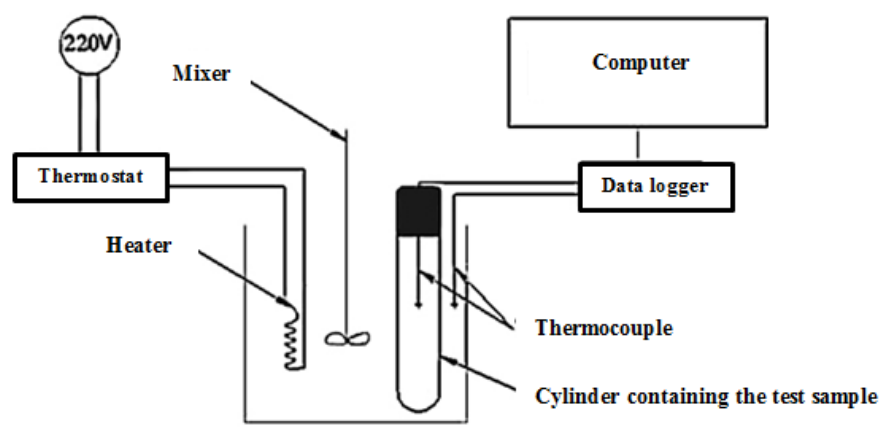

Figure 1: A Schematic of the used equipment in the experiment of the coefficients of the thermal diffusivity.

We obtain the value of $\theta$ of the relation 1 with recording the change of the temperature in the center of the cylinder in effect of the mal gradient between the sample of inside cylinder and water bath.

$$
\theta=\frac{T-T_{e}}{T_{0}-T_{e}}
$$

Which $\mathrm{T}$ is the change of recording temperature by data reader; $\mathrm{T}_{\mathrm{e}}$ is the temperature of water bath and $\mathrm{T}_{0}$ is the first temperature in the center of the sample. We obtain the coefficient of the thermal diffusivity from an equation (2) with drawing the diagram of $\operatorname{Ln}(\theta)$ in front of time $(t)$ and determine the slope of this diagram. These experimental procedures are done for four humidity surfaces of $20,40,60,82 \%$ and in temperature of $40,50,60,70 \mathrm{C}$ in 3 
repetitions. It is mentioned that the mean value of the temperature of materials $\left(\mathrm{T}_{0}\right)$ and the environmental temperature $\left(\mathrm{T}_{\mathrm{e}}\right)$ is a temperature which is calculated the value of the coefficient of thermal diffusivity in that.

$\alpha=\frac{1}{\tau}\left(\frac{R}{2.405}\right)^{2}$

\section{Fertilizes shear stress}

The manures shear stress is effective in consumption Energy of the Extruder. The manures shear stress is created in the screw movement of the cylindrical body. Therefore if we assume the mass of the cattle manure like the mass of soil we can measure the manures shear stress of the low dung with using of torque meter (figure 2-a) with is connected to the bar that has four blades.

The standards size of the diameter of four blades is $19 \mathrm{~mm}$ and the height of the blades is $29 \mathrm{~mm}$, and including the axis which is connected to the torque - meter (figure 2- b) The size of blades for move difficult materials is variable The relative area of the blade is are percent and is determined by using of the relation $(3)[1,2,4,8]$.

Area ratio $=\left[\frac{8 T(D-d)+\pi d^{2}}{\pi D^{2}}\right] \times 100$

D: the total with of blades which is measured with accuracy of $1 \mathrm{~mm}(\mathrm{~mm})$

T: The thickness of blades which is measured with accuracy of $0.01 \mathrm{~mm}(\mathrm{~mm})$

$\mathrm{d}$ : the diameter of the axis of blades which is measured with accuracy of $0.1 \mathrm{~mm}(\mathrm{~mm})$.

The manure shear stress is measured with use of relations (4), (5)

$K=\pi D^{2} \frac{H}{2} \times\left(1+\frac{D}{3 H}\right) \times 10^{-6}$

$\tau=\frac{M}{K}$

$\mathrm{H}$ : the height of blades (mm).

$\mathrm{K}$ : It is the constant and depends to the dimensions and from of blades.

M: The manures shear torque is in terms of Newton meter.

$\tau$ : The shear stress is in terms of kilo Pascal

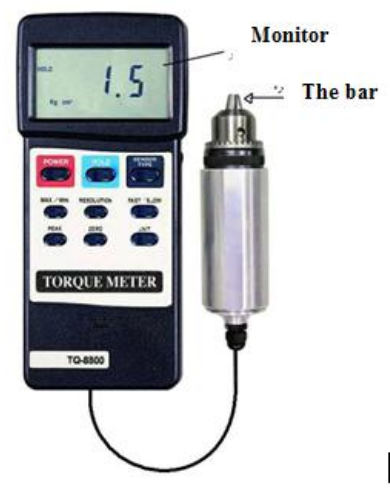

a) Torque meter

Figure 2: Shear stress measurement device 
The way of experiment is a way that is placed a bar which has four blades on the surface of the manures vertically and goes inside to the manures. The amount of depth which four blades go to the manure should be double of the height of blades (areal 70 to $80 \mathrm{~mm}$ ) or is a value that the manure on the surface of blades have not any movements when rotating four blades and in other side when it is entering in to the manure, four blades shouldn't any lateral and vibration movement and also shouldn't dig in the manure more than the height of the axis which is connected to the blades and when four blades get one depth that they can't dig in so the measured data's in reports $[1,2,4,8]$ for reminding the shear stress experiment from the pasty manure is done with humidities $40,50,60$, 70 percent at which pellet has the best stability. Experiments are done for determine the shear stress for working accuracy in four repetitions.

\section{Results and Discussion}

\section{The results of the coefficient of the manure thermal diffusivity $(\alpha)$}

Figure (3) shows the diagram of $\operatorname{Ln}(\theta)$ in front of the time of cooling the samples of the manures in temperature of $40 \mathrm{C}$ and different humidities. As it is determined in the figure (3) there is a linear relation with a negative slope between Ln $(\theta)$ and time of cooling. Also the amount of slope decreases with increasing the humidity surface. The relation between cooling and $\operatorname{Ln}(\theta)$ is obtained by use of the regression analysis for all humidities and tested temperatures Table (1) shows the parameters of the liners relation between the amount of R is 0.9994 to 0.9901 and the standard error $\left(\mathrm{e}_{\mathrm{s}}\right)$ is between 0.09656 to 0.01215 . The linear relation between the temperature logarithm and time of cooling in indicative the high accuracy of the coefficient of the thermal diffusivity which is calculated as we see in the table, the slope of lines (A) increases with increasing the temperature in the constant humidity.

Also in the constant temperature with increasing the humidity from $20 \%$ to $40 \%$ Anonymous the slope become increased and after that it has the decreasing procedure according to the amount of the slope of lines from drawing $\operatorname{Ln}(\theta)$ in front of time of cooling and giving the radius of the used cylinder in the experiment. The amount of $\boldsymbol{\alpha}$ is obtained from $2.11 \times 10^{-7}$ to $9.04 \times 10^{-8} \mathrm{M}^{2} / \mathrm{S}$.

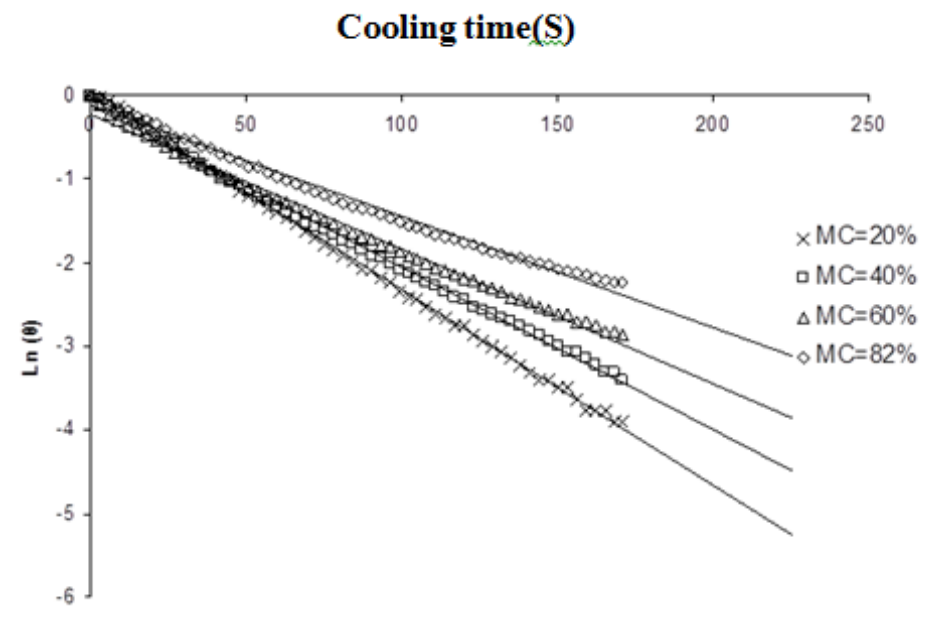

Figure 3: shows the diagram of $\operatorname{Ln}(\theta)$ in front of the time of cooling the samples of the manures in temperature of $40^{\circ} \mathrm{C}$ 
Table (1): Coefficients between $\operatorname{Ln}(\theta)$ and time of cooling $\operatorname{Ln}(\theta)=A t+B$ in temperatures and fasted humidities.

\begin{tabular}{|c|c|c|c|c|c|}
\hline \multirow{2}{*}{$\begin{array}{r}\text { Temperature } \\
\left({ }^{\circ} \mathrm{C}\right) \\
\end{array}$} & \multirow[t]{2}{*}{ Humidity(\%) } & \multicolumn{2}{|c|}{ Linear relationship parameters } & \multirow[t]{2}{*}{$\mathbf{R}^{2}$} & \multirow[t]{2}{*}{$\mathbf{e}_{\mathrm{s}}$} \\
\hline & & $\mathbf{A}$ & B & & \\
\hline \multirow{4}{*}{40} & 20 & $-0 / 01019$ & $-0 / 10614$ & $0 / 9917$ & $0 / 05977$ \\
\hline & 40 & $-0 / 01113$ & $-0 / 15968$ & 0/9970 & $0 / 09656$ \\
\hline & 60 & $-0 / 01024$ & $-0 / 22818$ & 0/9901 & $0 / 08052$ \\
\hline & 82 & $-0 / 00897$ & $-0 / 02039$ & $0 / 9965$ & 0/07433 \\
\hline \multirow{4}{*}{50} & 20 & $-0 / 01387$ & $-0 / 09751$ & $0 / 9973$ & $0 / 06497$ \\
\hline & 40 & $-0 / 01495$ & $-0 / 03698$ & 0/9994 & $0 / 02481$ \\
\hline & 60 & $-0 / 01338$ & $-0 / 33803$ & 0/9902 & $0 / 01215$ \\
\hline & 82 & $-0 / 01169$ & $-0 / 12271$ & 0/9904 & $0 / 06488$ \\
\hline \multirow{4}{*}{60} & 20 & $-0 / 01709$ & $-0 / 13685$ & $0 / 9922$ & $0 / 08421$ \\
\hline & 40 & $-0 / 01894$ & $0 / 021973$ & 0/9992 & $0 / 03315$ \\
\hline & 60 & $-0 / 01709$ & $-0 / 26793$ & 0/9972 & $0 / 07254$ \\
\hline & 82 & $-0 / 01621$ & $0 / 001406$ & 0/9972 & $0 / 06627$ \\
\hline \multirow{4}{*}{70} & 20 & $-0 / 02155$ & $-0 / 23461$ & $0 / 9924$ & $0 / 07735$ \\
\hline & 40 & $-0 / 02324$ & $0 / 096352$ & 0/9972 & $0 / 04612$ \\
\hline & 60 & $-0 / 02196$ & $-0 / 32612$ & 0/9957 & $0 / 07668$ \\
\hline & 82 & $-0 / 02061$ & 0/016771 & 0/9913 & 0/07796 \\
\hline
\end{tabular}

The relation (6) shows the share diverse between a humidity and temperature in tested conditions. According to high accuracy of obtained model $\left(\mathrm{R}^{2}=0.991\right)$ we can use from that for estimating $\boldsymbol{\alpha}$ of the manures in tested conditions.

$\alpha=6.404 \times 10^{-10} T+1.24 \times 10^{-9} M R+2.865 \times 10^{-11} T^{2}-1.464 \times 10^{-11} M R^{2}$

The values of $\boldsymbol{\alpha}$ from experiments in front of $\boldsymbol{\alpha}$ is shown in figure (5) which is obtained from relation (6) in with about 45 angle fit on them $\left(y=0.999 \times-8 \times 10^{-9}\right)$ which is indicative the high accuracy of obtained model.

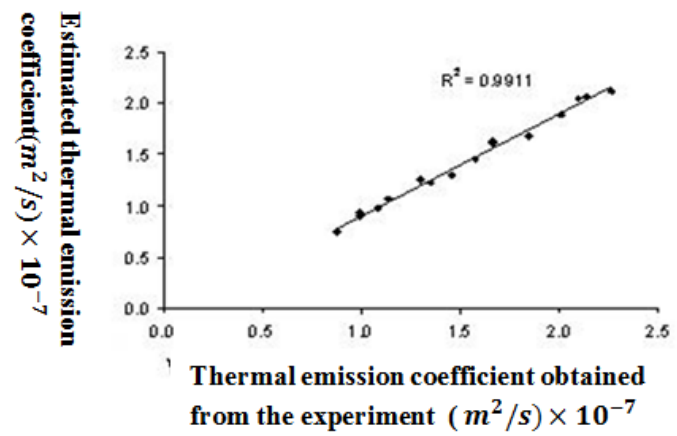

Figure 4: the comparison of $\alpha$ obtained from experiments' and $\alpha$ obtained from the model of the relation of (6).

Figure (5) Shows the effect of the amount of humidity as we see, with increasing the humidity from $20 \%$ to $40 \% \boldsymbol{\alpha}$ has an increasing procedure and after that decreases in more than $40 \%$ humidities. And also with increasing the amount to the temperature from 40 to $70 \mathrm{C}$, The curves placed in higher levels. 


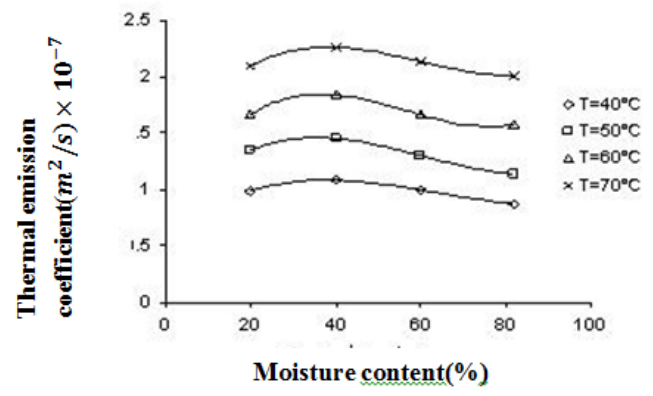

Figure 5: The changes of $x$ with increasing the humidity in temperatures $40,50,60,70 \mathrm{C}$

Figure 6 shows the effect of increasing the temperature on the $\mathrm{x}$ in tested humidities. As it is determined in the figure, with increasing the temperature, the amount of $\mathrm{x}$ increases linear. And also the related line to the humidity surface is place from the rest of humidity surfaces which it compatibilities with the result of figure 5 .

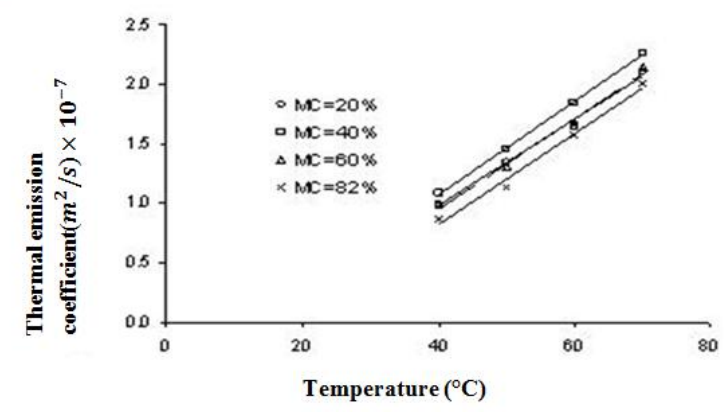

Figure 6: The changes with increasing the temperature in humidities 20, 40, 60, $82 \%$.

\section{The results of the manures shear stress experiments:}

This experiment is done for the cattle manure with humidities 70,60, 50, 40 percent and each one is done for 4 repetitions According to the figure (7), we see with increasing the percent of the humidity of the cow dung, the shear stress decreases and this is due to with increasing the humidity, inter molecular bonding forces loose and we need lower force for cutting the needed manures.

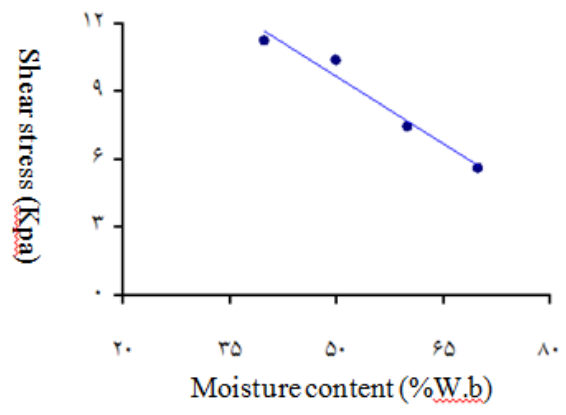

Figure 7: The change of the manures shear stress in terms of the humidity contents.

The relation (7) is indicative the relation between the manure and shear stress in meshes $10(2 \mathrm{~mm})$ to $50(0.3 \mathrm{~mm})$.

$\tau=-0.1977 \mathrm{Mc}+19.516 \quad \mathrm{R}^{2}=0.96$ 
This experiment shows that it is obtained the most shear stress between the humidity contents of 40 and 50 . The shear stress has a very important part in the first stability of the pasty manure in going outside from an opening format and also an obtained data's from this part has compatibilities with results of other researchers [9].

\section{References}

[1] BS1377: Part 7:1990 Method 3- Determination of shear strength by the laboratory vane method.

[2] Burton, C.H., 1997.Manure Management - Treatment strategies for sustainable agriculture. Silsoe Research Institute, Bedford, UK.

[3] El-Ahraf, A., Willis, W.V.1996. Management of Animal Waste: Environmental Health Problems and Technological Solutions. Praeger Publishers, Westport, USA.

[4] Heckel, R.W. 1961. An analysis of powder compaction phenornena. Transactions of the Metallurgical Society of AIME $221: 1001-1008$.

[5] Landry. H, Laguë. C., Roberge. M. 2004. Physical and Rheological Properties of Manure Products. Applied Engineering in Agriculture, Vol. 20(3): 277-288.

[6] Mohsenin, N. N. 1980. Thermal Properties of Foods and Agricultural Materials. New York, NY: Gordon and Breach, Science Publishers, Inc.

[7] Munoz-Hernandez, G., Dominguez- Dominguez, J., Alvarado-Mancilla, O. 2006. An Easy Laboratory Method for Optimizing the Parameters for the Mechanical Densification Process: An Evaluation with an Extruder. Agricultural Engineering International: the GIGR Journal. Manuscript PM 06015. Vol. VIII.

[8] New Zealand Geotechnical Society Inc Test Method for Determining the Vane Shear Strength of a Cohesive Soil Using a Hand Held Shear Vane, August 2001

[9] Sadin, A. 2007 Design of Manure Collection Device, Master's thesis, Mechanical Engineering, Agricultural Machines, Faculty of Agriculture, Ferdowsi University of Mashhad. 